\title{
Effect of polysaccharides on the hydration of cement suspension
}

\author{
A.Peschard ${ }^{1}$, A.Govin* ${ }^{1}$, J.Pourchez ${ }^{1}$, E.Fredon ${ }^{2}$, L.Bertrand ${ }^{3}$, S.Maximilien $^{3}$, B.Guilhot ${ }^{1}$ \\ ${ }^{1}$ Ecole Nationale Supérieure des Mines de Saint Etienne, Centre SPIN, Department of \\ Materials Engineering (PC2M), LPMG: process in granular media laboratory CNRS \\ UMR 5148, 158 cours Fauriel 42023 Saint Etienne cedex, France \\ ${ }^{2}$ Laboratoire de Chimie des Substances Naturelles, Faculté des Sciences et Techniques, \\ 123 Avenue Albert Thomas , 87060 Limoges \\ ${ }^{3}$ INSA-Lyon, Group of Metallurgy and Materials Science (GEMPPM) UMR 5510, 20 \\ Avenue Albert Einstein, 69621 Villeurbanne cedex \\ ${ }^{\diamond}$ A.Peschard and A.Govin have contributed equally to this work \\ * Corresponding author Tel: (33) 4774202 74; fax: (33) 477499694 \\ E-mail address: govin@emse.fr
}

\begin{abstract}
This work compares the effects induced by polysaccharides on the hydration of cement. It also brings new insights into the interaction mechanisms between these two components. Several parameters such as structure, concentration, average molecular weight, and the soluble fraction value of the polysaccharides were examined. The hydration of cement was monitored by conductivity measurement, and ionic chromatography. The influence of polysaccharide structure on the kinetics of cement hydration was revealed. The extent of retardation increases when polysaccharide concentration rises. Dextrins with lower average molecular weights compared with starches favor a higher soluble fraction value and further retard hydration. The growth of hydrates seemed to be more affected by the presence of these admixtures than did the dissolution of anhydrous particles or the nucleation of former hydrates.
\end{abstract}


Keywords : C Ionic conductivity, Cement, B Composites, C Chemical properties, Polysaccharides, Hydration.

\section{Introduction}

Among the organic admixtures widely used in the formulation of mortars and concrete, polysaccharides are polymers which can be equally classified in water-reducers, set-retarders, and water retention agents.

Numerous authors have demonstrated that the properties of mortar and concrete can be significantly modified at fresh state as well as at hardened state by the addition of polysaccharides [1-8].

Several mechanisms were proposed to explain the interactions between cement and set-retarders (i.e. sugars or carboxylic acids) [9-15]. Some authors focused their studies on interaction with anhydrous surfaces. For Hansen [16], the adsorption onto anhydrous particles could occur and protect surfaces from initial attack by water. Susuki [17] proposed that the retarding action of admixtures could be linked to the precipitation of insoluble calcium salts at the surface of anhydrous particles even though a clear correlation between solubility and retarding ability of carboxylic acids was not established.

Other studies pointed out that interactions between admixtures and hydrates could also exist. According to Thomas and Birchall [18], the retarding action of sugars is explained in terms of adsorption onto and poisoning of hydrates surfaces. Young [19] suggested that an incorporation of admixtures into crystal lattices could occur. For example, in the case of $\mathrm{C}_{3} \mathrm{~A}$ hydration, he proposed that organic compounds could enter 
the interlayer region and stabilize hexagonal hydrates like $\mathrm{C}_{4} \mathrm{AH}_{13}$ at the expense of the cubic form $\mathrm{C}_{3} \mathrm{AH}_{6}$. However, in the case of $\mathrm{C}_{3} \mathrm{~S}$ hydration, Popova [20] showed that polymer-CSH interaction was restricted to adsorption. Indeed no significant structural modification of $\mathrm{CSH}$ were observed by ${ }^{29} \mathrm{Si}$ NMR characterization.

Hence a mechanism describing the influence of set retarding admixtures on cement hydration is still not well elucidated. In order to bring new insights, the present study focuses on the hydration of cement in presence of compounds widely used in mortars i.e. polysaccharides. The few works on this topic were limited to physico-chemical phenomenon occurring in a system that only contains cement and monosaccharides $[11,13,15,21]$. Most previous studies were carried out in concentrated media (i.e. Water-tocement weight ratio $\mathrm{W} / \mathrm{C}$ inferior to 1) $[12,13,21]$. The present work was performed on cement suspensions $(\mathrm{W} / \mathrm{C}=20)$, by means of conductivity measurement and ionic chromatography, to identify parameters responsible for the set retarding ability of these admixtures. The advantage to work on dilute media is to extend the $\mathrm{x}$-axis corresponding to time. The phenomena relevant to hydration i.e dissolution, nucleation, and growth of hydrates are more easy to observe at $\mathrm{W} / \mathrm{C}=20$ than at ratio inferior to 1 .

\section{Experimental}

\subsection{Raw materials}

Two Portland cements from Calcia company were studied : a white cement CPA CEM I 52.5, and a grey cement PMES 42.5 according to the French standard NF P 15-301. They were selected in order to determine the effect of cement composition on set retarding 
ability of polysaccharides. Chemical composition and mineralogical phases calculated by Bogue approximation [22] are respectively listed in Table 1.

The five polysaccharides studied were supplied by several admixtures producers and were of different types i.e. a cellulose ether (CE), a starch ether (SE), a native starch (NS), a white dextrin (WD) and a yellow dextrin (YD), the last 2 prepared from NS. Properties of these polysaccharides are given in Table 2.

\subsection{Methods of investigation}

In each case, cement and polysaccharide powders were mixed together for 2 periods of 2 minutes using a shaker-mixer (Wab, Turbula, Germany). Unless otherwise stated, polysaccharide-to-cement weight ratio $(\mathrm{P} / \mathrm{C})$ was equal to $0.5 \%(\mathrm{w} / \mathrm{w})$ and experiments were carried out in triplicate.

The conductivity equipment consisted of a $25^{\circ} \mathrm{C}$ thermostated reactor that contains 11 of deionised water, a platinum electrode and a conductimeter (Tacussel CD 810, France). Previous to each experiment a calibration was performed with a $0.1 \mathrm{M} \mathrm{KCl}$ solution.

Additional data were obtained by the determination of specific ion concentrations (calcium, sulfate and silicate) using ionic chromatography. This was performed on a Dionex apparatus, composed of a GP50 pump, a CS12A column for cation analysis and a AS11HC column for anions, a CD20 conductimetric detector and an AD25 UV-Vis detector. From the reactor containing the cement suspension, samples of $10 \mathrm{ml}$ were 
collected. Two volumes of $1 \mathrm{ml}$, from previous samples, were diluted 10 times and used to determine calcium and sulfate concentrations. The analysis conditions are given in Table 3.

Dissolution of cement in presence of polysaccharides was also monitored by conductivity measurement. The analysis were performed in very dilute media, i.e., W/C equal to 8000, since Comparet [23] showed that no saturation with respect to hydrates occured in these conditions. This ratio allows to isolate the dissolution of anhydrous particles during the hydration of cement. Prior to measurement, a calibration was performed with a $10^{-2} \mathrm{M} \mathrm{KCl}$ solution.

To highlight the polysaccharide-cement interaction, the quantity of native polymer in a cement filtrate was determined. Samples and Control samples were prepared by introducing polysaccharides at 1 g. $1^{-1}$ in cement suspension and cement filtrate respectively. In both cases, several steps were realised i.e. filtration, centrifugation, dialysis as described in Fig. 1. The samples were analysed by Gel Permeation Chromatography (GPC) equipped with a pump (WATERS 916, USA), a column (TOSOHAAS TSK GEL GMPWXL $7.8 \mathrm{~mm} \times 30 \mathrm{~cm}$, Germany) conditioned in a furnace at $30{ }^{\circ} \mathrm{C}$ and a refractometer (WATERS 410, USA). A flow of deionised water (millipore, mQ, USA), previously in-line degassed, was maintained at $0.5 \mathrm{ml} \cdot \mathrm{mn}^{-1}$. Calibration was carried out by the injection of polymaltotrioses samples (Shodex P-82 standards). The quantity of polysaccharide non-adsorbed and not decomposed, determined in cement phases was defined by Eq. 1

$$
\% P=\frac{A_{C F}}{A_{C S}} \times 100
$$

where $\mathrm{A}_{\mathrm{CF}}$ and $\mathrm{A}_{\mathrm{CS}}$ represent the peak area of the polysaccharide in the cement filtrate and in the control sample respectively. 


\section{Results}

\subsection{Hydration of $C_{1}$}

The conductimetric curve of a cement suspension presents different steps (Fig. 2) as described by Comparet [23], and Maximilien [24].The retarding ability of polysaccharide on the hydration of cement was correlated to the slope value before the maximum of the conductimetric curve. A low slope value represents a high slowing down of the hydration rate of cement. Fig. 3 shows that admixture CE has little effect on the conductimetric curve contrary to SE which slows hydration significantly and to YD which blocks it for approximately 10 hours.

The time at which portlandite precipitation occurred was defined by $t_{\lambda \max }$. The order of portlandite precipitation is as follows :

$$
\mathrm{C}_{1}<\mathrm{C}_{1}+\mathrm{CE}<\mathrm{C}_{1}+\mathrm{SE}<\mathrm{C}_{1}+\mathrm{YD} \text {. }
$$

These results clearly showed that the polysaccharide chemical structure is a major parameter and has governed the first hours of the hydration rate of cement. The Slope and $t_{\lambda \max }$ values of corresponding cement suspensions are given in Table 4.

\subsection{Influence of polysaccharide SE and YD}

\subsection{Influence of concentration}

The increase of $\mathrm{P} / \mathrm{C}$ ratio and especially for $\mathrm{SE}$, induces an extended reduction of the hydration rate of cement since the slope decreases. It indicates that the balance between 
dissolution of anhydrous particles and precipitation of hydrates is significantly modified by the addition of SE. The minimum $\mathrm{YD} / \mathrm{C}_{1}$ ratio where a blocking effect was observed was equal to $0.4 \%$. In contrast the delay observed when $\mathrm{YD} / \mathrm{C}_{1}=0.5 \%$ (10 hours) underwent a large increase if $\mathrm{YD} / \mathrm{C}_{1}=1 \%$ (delay $46 \mathrm{~h}$ ). Corresponding values of slope and blocking effect duration are listed on Table 4.

\subsection{Influence of polysaccharides addition timing}

Polysaccharides were added to cement immediately or delayed from 5 minutes to 90 minutes. For $0.5 \%$ YD addition, the duration of the blocking effect gradually decreased and became negligible beyond 30 minutes (Fig. 4). An increase in YD concentration up to $1 \%$ induced a plateau wich was still observed for a delayed addition of 30 minutes but not for a delay of 90 minutes. Consequently an increase of the delay to add YD requires a higher concentration to observe a plateau. Two explanations are possible, YD could adsorb either on hydrated or on anhydrous particles. In the first case, the hydrated particles are more numerous and have a larger specific surface area than anhydrous particles. Hence to inhibit completely the hydration a higher amount of YD is necessary. In the second case, the adsorption of YD could occur on anhydrous particles. However, they are less accessible due to the formation of hydrates when the addition is delayed. In the case of the delayed addition of SE, the slope increases but does not recover to the value for the neat cement. This shows that YD and SE do not act in the same way on the hydration of cement.

\subsection{Effect of starch dextrinization on cement hydration}


To explain the singular effect of $\mathrm{YD}$, the hydration of cement in the presence of Native starch (NS) and dextrins (WD, YD) was more specifically studied. Dextrins were prepared by a thermal treatment $\left(140\right.$ to $\left.180{ }^{\circ} \mathrm{C}\right)$ in hydrochloric acid of NS (Evans [25], Satterwaite [26]) by the Roquette Company (France). The admixture WD presents a weak conversion from starch to dextrins in contrast to YD. A lower average molecular weight favours a higher soluble fraction value which is, according to the supplier, greater than 90 $\%$, between 5 and $35 \%$, and less than $5 \%$ for YD, WD and NS respectively. Conductivity measurement shows that NS has no effect, WD slows down and YD blocks for 10 hours, the hydration of cement (Fig. 5). Interaction between WD and cement was limited since more than $80 \%$ of WD (determined by GPC Eq. 1) was still present in cement suspension. Furthermore, the cement composition does not seem to have any effect on the set retarding ability of dextrin YD. Similar to the case for cement $\mathrm{C}_{1}$, a blocking effect on $\mathrm{C}_{2}$ hydration occurs for 10 hours when $0,5 \%$ of YD was added.

The increase of $\mathrm{WD} / \mathrm{C}$ ratio from 0.5 to $2.5 \%$ leads to a blocking effect and suggests that the difference in the set retarding ability of WD and YD is more attributed to the gap in the soluble fraction value than to the difference in the average molecular weights.

\subsection{Hypothesis concerning interaction mechanisms}

\subsection{Highlight of cement polysaccharide interaction}

In order to investigate the cement polysaccharide interaction, the proportion of admixture in the filtrate was determined by GPC according to Eq. 1. This protocol is a way to measure the quantity of polysaccharide adsorbed and/or decomposed by mineral phases. 
Results reveal that more than $80 \%$ of $\mathrm{CE}$ quantity was still present in the filtrate. In contrast $\mathrm{C}_{1}+\mathrm{SE}$ and $\mathrm{C}_{1}+\mathrm{YD}$ exhibit residual concentrations of admixture in the filtrate of less than $10 \%$. Consequently it indicates that CE was not "trapped" contrary to the most efficient set retarding admixtures i.e. SE and YD which are probably adsorbed and/or decomposed by cement.

\subsection{Effect of polysaccharides on the dissolution of cement}

The dissolution of cement was studied on very diluted suspensions $(\mathrm{W} / \mathrm{C}=8000)$. Even though these under-saturated conditions are very far from the hydration at W/C equal to 20, they make it possible to isolate the dissolution phenomena. Any differences, observable between the formula $\mathrm{C} 1$ and $\mathrm{C} 1+200 \% \mathrm{YD}$, is hidden by the repeatability variation. Consequently the addition of polysaccharides at $\mathrm{P} / \mathrm{C}$ ratio from $0.5 \%$ to $200 \%$ does not affect significantly the dissolution rate (Fig. 6). Hence a mechanism which postulates that the retardation is linked to an adsorption of organic molecules on anhydrous particles as proposed by Seligmann [27] does not seem to be valid in the case of cement admixed with polysaccharides.

\subsection{Effect of polysaccharides on the interstitial phase}

The studying phase supplies supplementary information compared with conductivity measurement which only gives a global evolution. Fig.7 shows that calcium concentration evolution is similar to conductimetric curves. The increase of calcium concentration for suspensions that contain CE or SE respectively is equivalent to and much lower than that for pure cement. The addition of YD creates a blocking effect in the rise of 
calcium concentration equivalent to the plateau observed on the conductimetric curves. Consequently it seems that calcium diffusion through the solution is inhibited.

The Sulfate concentration decreases since this species is consumed to react with $\mathrm{C}_{3} \mathrm{~A}$ to form ettringite (Fig. 8). For all formulae, in the first 30 minutes the sulfate concentration decreases indicating that ettringite is forming. Beyond this period, the concentration decrease is similar to that of neat cement for the suspensions $\mathrm{C}_{1}+\mathrm{NS}$ and $\mathrm{C}_{1}+\mathrm{CE}$ but is lower for suspensions that contain SE and YD. These observations for the latter formula could indicate either a decrease in the precipitation rate and an unchanged dissolution rate or a reduction in the dissolution and the precipitation rates due to the selfregulation process. From this results it could be assumed that the beginning of $\mathrm{C}_{3} \mathrm{~A}$ hydration, leading to ettringite formation, is not modified and that the ettringite amount is then stabilized for $\mathrm{C}_{1}+\mathrm{SE}$ and $\mathrm{C}_{1}+\mathrm{YD}$ samples. This observation will induce a delay in the conversion of ettringite to monosulfoaluminate phase. These results are in good accordance with those obtained in concentrated media which revealed, a stabilisation of ettringite and a lower gypsum consumption, for cements formulated with SE or YD [28].

The concentration of silicate ions rises rapidly as a consequence of $\mathrm{C}_{3} \mathrm{~S}$ dissolution and then subsequently decreases due to the nucleation of CSH. In all the tested formula within the first hour of hydration, silicate concentration decreases. This suggests that polysaccharides do not affect significantly $\mathrm{CSH}$ nucleation rate. Nevertheless for $\mathrm{C}_{1}+\mathrm{YD}$, a plateau of silicate concentration is observed (results not shown). This phenomena could be linked to an adsorption of YD on CSH nuclei, forming protective barriers which inhibit further hydration.

\section{Conclusion}


This study revealed that it was difficult to establish a global mechanism of interaction between cement and polysaccharides since it seems to depend on the mineralogical phase studied and the admixture chemical structure. Nevertheless interesting results were obtained. First, this work reveals the importance of the chemical nature of the polysaccharides. The set retarding ability decreases in the order $\mathrm{YD}>\mathrm{SE}>\mathrm{WD}>\mathrm{CE}$. Second, a higher $\mathrm{P} / \mathrm{C}$ ratio leads to an extended delay in hydration. Third, starch dextrinization leads to a higher soluble fraction value and hence to a higher set retarding effect than native starch.

\section{Acknowledgement}

The authors acknowledge the financial support of Weber \& Broutin company (Servas, France) and Rhône-Alpes Region. 


\section{References}

[1] D.R. Dewacker, B. Mcad, Cement mortar systems using blends of polysaccharides and cold-water-soluble unmodified starches, US Patent, 5, 575, 840, 1996.

[2] H. Yamamuro, Property of new polysaccharide derivative as a viscosity agent for self compacting concrete, Proceeding of the First International Rilem symposium on self compacting concrete, Stockholm, Sweden 1999, pp. 449-459

[3] V.A. Ghio, P.J.M. Monteiro, The effects of polysaccharide gum additives on the shotcrete process, ACI Materials Journal 95, 1998, 2, 152-157.

[4] V.A.Ghio, P.J.M.Monteiro, L.A. Demsetz, The rheology of fresh cement paste containing polysaccharide gums, Cem Concr Res, 1994, 24 2, 243-249.

[5] Y.Tanaka, T.Uryu, M.Yaguchi, Cement compositions containing a sulfated polysaccharide and method, US Patent, 5, 573, 589, 1996.

[6] K.Hayakawa, T.Soshiroda, An experimental study on the concrete containing cellulose ether, Transportation of Japan Concrete Institute, 1985, 7, 17-24.

[7] K.Hayakawa, T.Soshiroda, Effects of cellulose ether on bond between matrix and aggregate in concrete, Adhesion between polymers and concrete proceedings 1986, pp. 2231. 
[8] N.K.Singh, P.C.Mishra, V.K.Singh, K.K.Narang, Effects of hydroxyethyl cellulose and oxalic acid on the properties of cement, Cem.Concr.Res 2003, 33, 1319-1329.

[9] G.M. Bruere, Importance of mixing sequence when using set retarding agents with portland cement, Nature, 1963, 199, 32-33.

[10] G.M. Bruere, Set retarding effects of sugars in Portland cement pastes, Nature, 1966, 212, 502-503.

[11] N.Tenoutasse, N.B.Singh, Effect of glucose and calcium gluconate on the hydration of Portland Cement, Ind. J. Tech, 1978, 16, 184-189.

[12] N.B.Singh, Effect of gluconates on the hydration of cement, Cem.Concr.Res, 1976, 6, 455-460.

[13] U.Ludwig, C.Urrutia, Influence of sucrose on the setting of Portland cement, Proceedings of the $8^{\text {th }}$ International Congress on the chemistry of cement, Rio de Janeiro, $520-522$.

[14] S.Diamond, Interactions between cement minerals and hydroxycarboxylic-acid retarders : I, apparent adsorption of salicylic acid on cement and hydrated cement compounds, J. Am. Ceram. Soc, 1971, 54 nº, 273-276.

[15] K.Luke, G.Luke, Effect of sucrose on retardation of Portland cement, Adv. Cem. Res. $2000,12 \mathrm{n}^{\circ} 1,9-18$. 
[16] W.C.Hansen, Actions of calcium sulfate and admixtures in portland cement paste, Symposium on admixtures in concrete, ASTM Technical publication, 266, 1960, pp. 3-37.

[17] S.Suzuki, S.Nishi, Influence of saccharides and other organic additives on the hydration of Portland cement, Rev $13^{\text {th }}$ General Meeting of the Japan Cement Engineering Association, 1959, pp. 34-35.

[18] N.L.Thomas, J.D.Birchall, The retarding action of sugars on cement hydration, Cem.Conc.Res, 1983, 13, 830-842.

[[19] J.F.Young, Effect of organic compounds on the interconversions of calcium aluminate hydrates : Hydration of Tricalcium aluminate, J.Am.Ceram.Soc., 1970, 53 n², 65-69.

[20] A. Popova, G. Geoffroy, M-F. Renou-Gonnord, P. Faucon, E. Gartner, Interactions between polymeric dispersants and calcium silicate hydrate, J.Am.Ceram.Soc., 2000, 83 (10), 2556-2560.

[21] M.C. Garci Juenger, H.M. Jennings, New insights into the effects of sugar on the hydration and microstructure of cement pastes, Cem.Concr.Res., 2002, 32, 393-399.

[22] H.F.W Taylor, Cement Chemistry, Academic Press, New York, 1990, pp 62-63. 
[23] C.Comparet, A.Nonat, S.Pourchet, J.P.Guicquéro, E.Gartner, M.Mosquet, Chemical interaction of Di-Phosphonate terminated monofunctional polyoxyethylene superplasticizer with hydrating tricalcium silicate, Proceedings of the $6^{\text {th }}$ CANMET/ACI International Conference on superplasticizers and other chemical admixtures in concrete, Ed V.M.Malhotra, SP195-5, 1997, pp. 61-74.

[24] S. Maximilien, J. Pera, M. Chabannet, Study of the reactivity of clinkers by means of the conductometric test, Cem.Concr.Res., 1997, 27, 63-73.

[25] R.B. Evans, O.B. Wurzburg, Production and use of starch dextrins, in: Starch Chemistry and Technology, Eds R.L.Whistler, E.F.Paschall, Academic Press, New-York and London, 1967, Chap XI, pp 254-276.

[26] R.W. Satterthwaite, D.J. Iwinski, Starch Dextrins, in: Industrial gums : Polysaccharides and their derivatives, Ed R.L.Whistler, Academic Press, New York and London, 1973, Chap XXVI, pp 577-587.

[27] P.Seligmann, N.R.Grenning, Studies of early hydration reactions of portland cement by X-ray diffraction, Highw.res.rec. 62 (1964) 80-105.

[28] A.Peschard, A.Govin, P.Grosseau, B.Guilhot, R.Guyonnet, Effect of polysaccharides on the hydration of cement pastes at early ages, Cem.Conc.Res., 2004, 34, 2153-2158 
Fig. 1. Sample preparation previous to proportioning polysaccharides in cement suspension
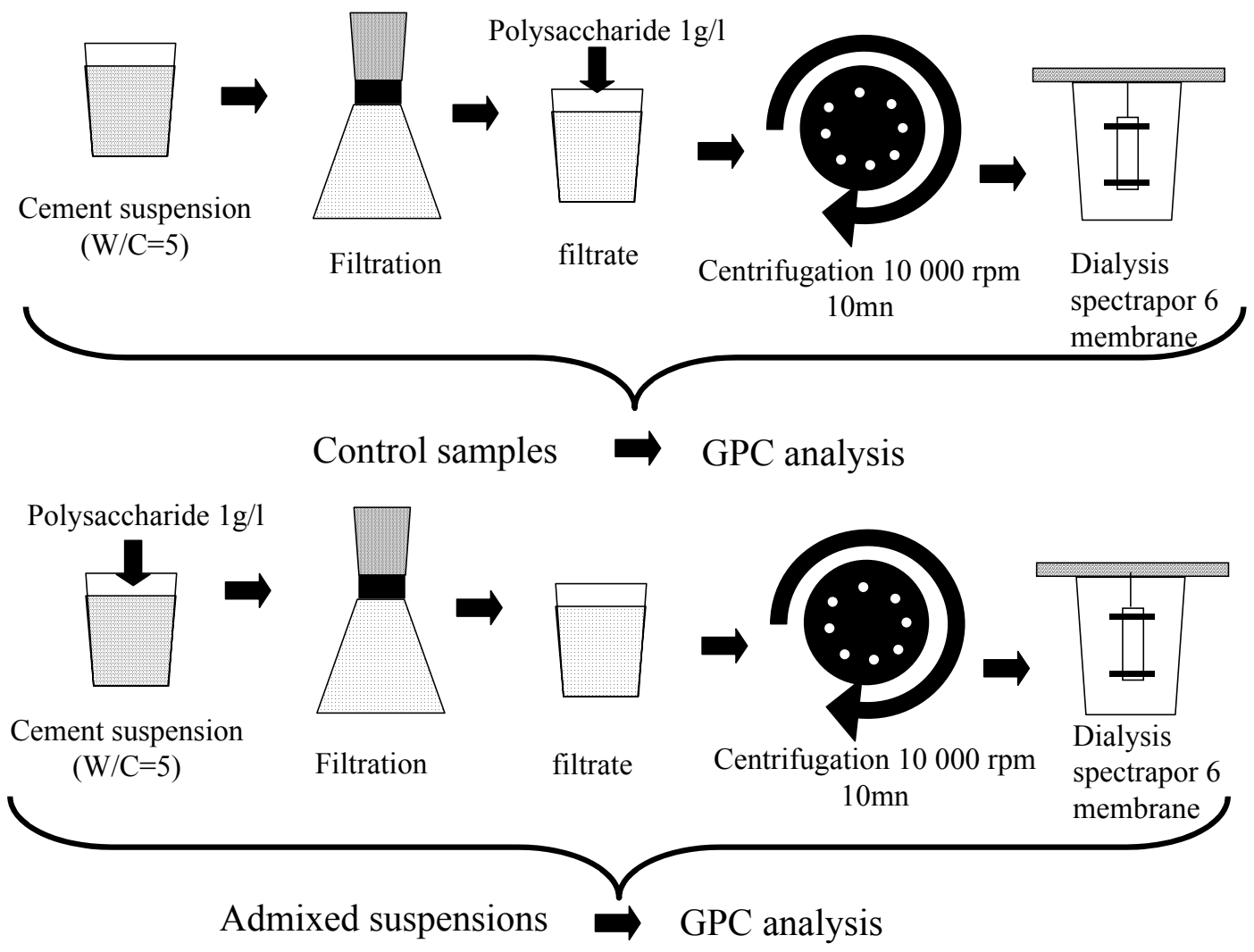
A.Peschard ${ }^{1}$, A.Govin* ${ }^{1}$, J.Pourchez ${ }^{1}$, E.Fredon ${ }^{2}$, L.Bertrand $^{3}$, S.Maximilien ${ }^{3}$, B.Guilhot ${ }^{1}$ 
Fig. 2. Different steps of a conductimetric curve

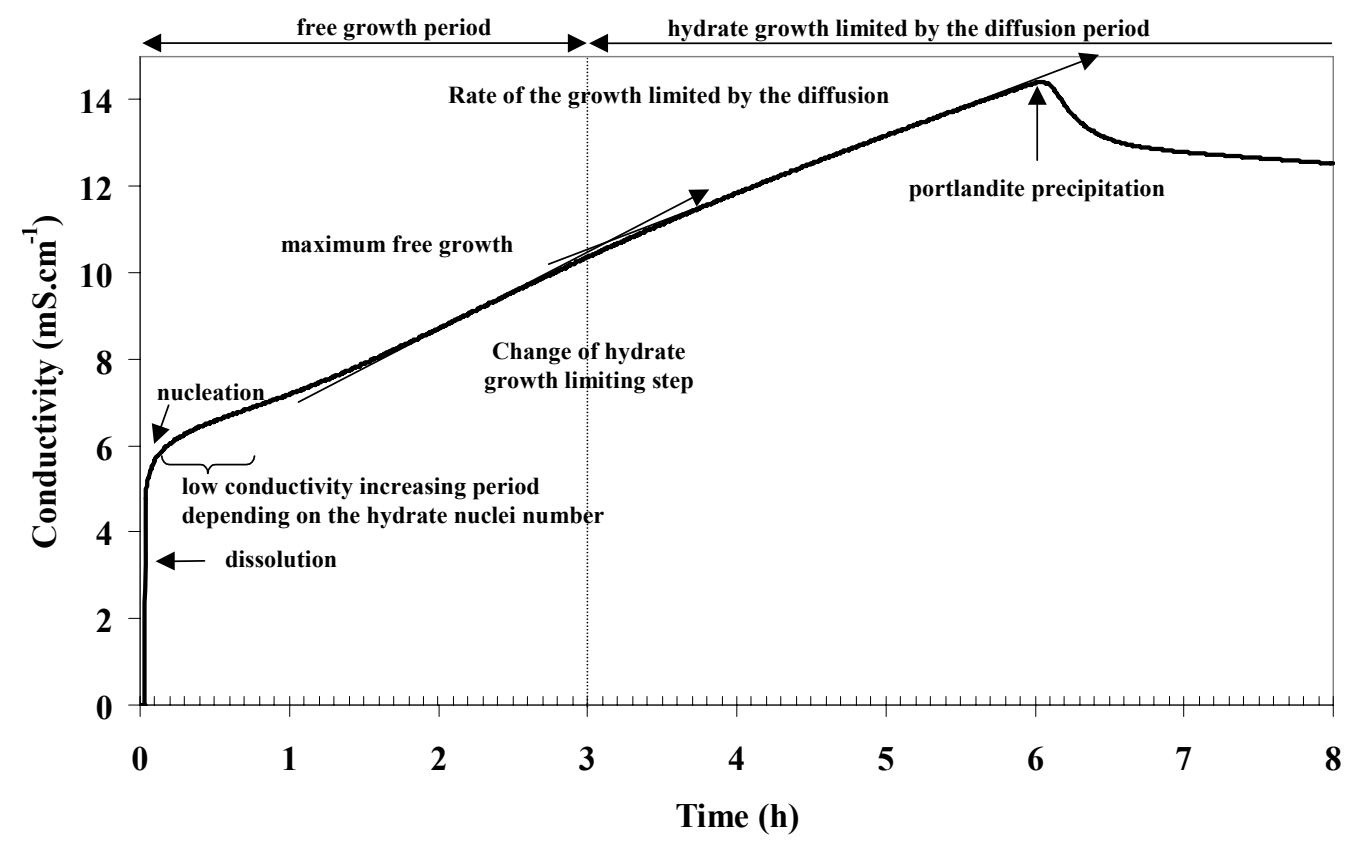




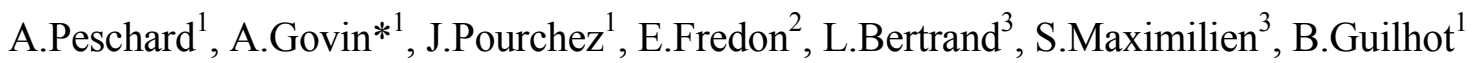


Fig. 3. Effect of the chemical nature of polysaccharides on cement hydration

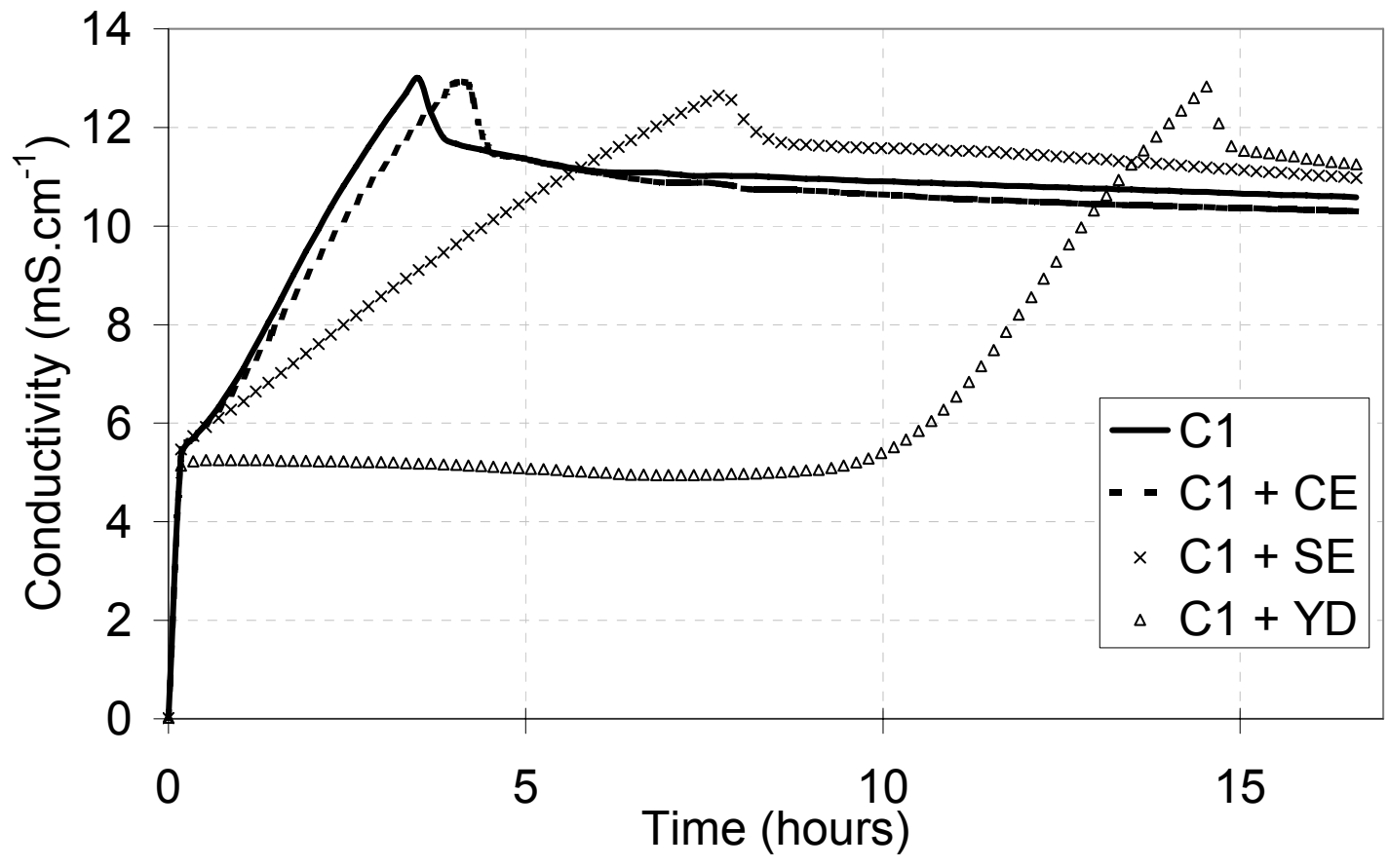


A.Peschard ${ }^{1}$, A.Govin* ${ }^{1}$, J.Pourchez ${ }^{1}$, E.Fredon ${ }^{2}$, L.Bertrand $^{3}$, S.Maximilien ${ }^{3}$, B.Guilhot ${ }^{1}$ 
Fig. 4. Effect of a delayed addition of $0.5 \% \mathrm{YD}$ on cement $\mathrm{C}_{1}$ hydration

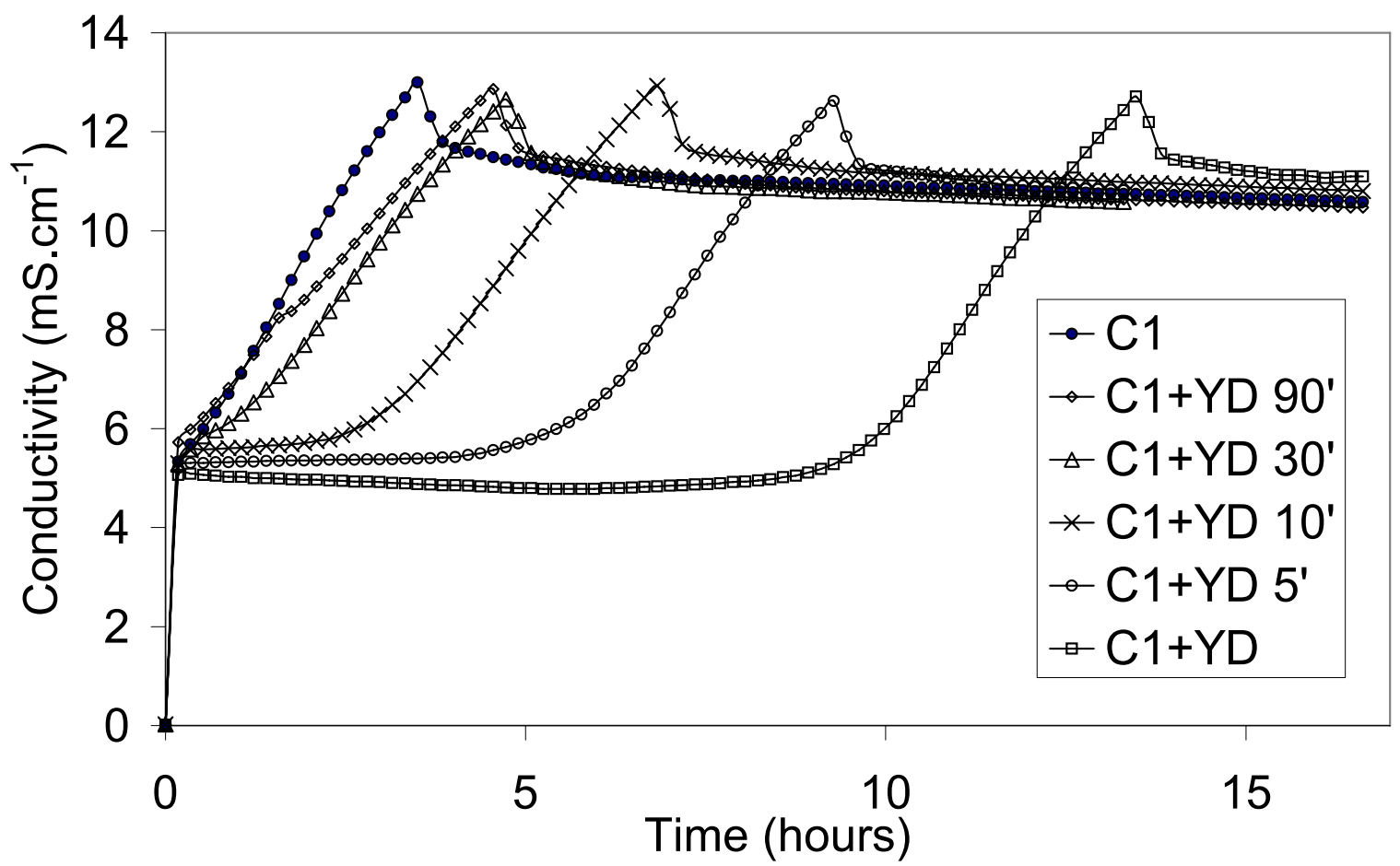


A.Peschard ${ }^{1}$, A.Govin* ${ }^{1}$, J.Pourchez ${ }^{1}$, E.Fredon ${ }^{2}$, L.Bertrand $^{3}$, S.Maximilien ${ }^{3}$, B.Guilhot ${ }^{1}$ 
Fig. 5. Effect of dextrinization on the conductimetric curves

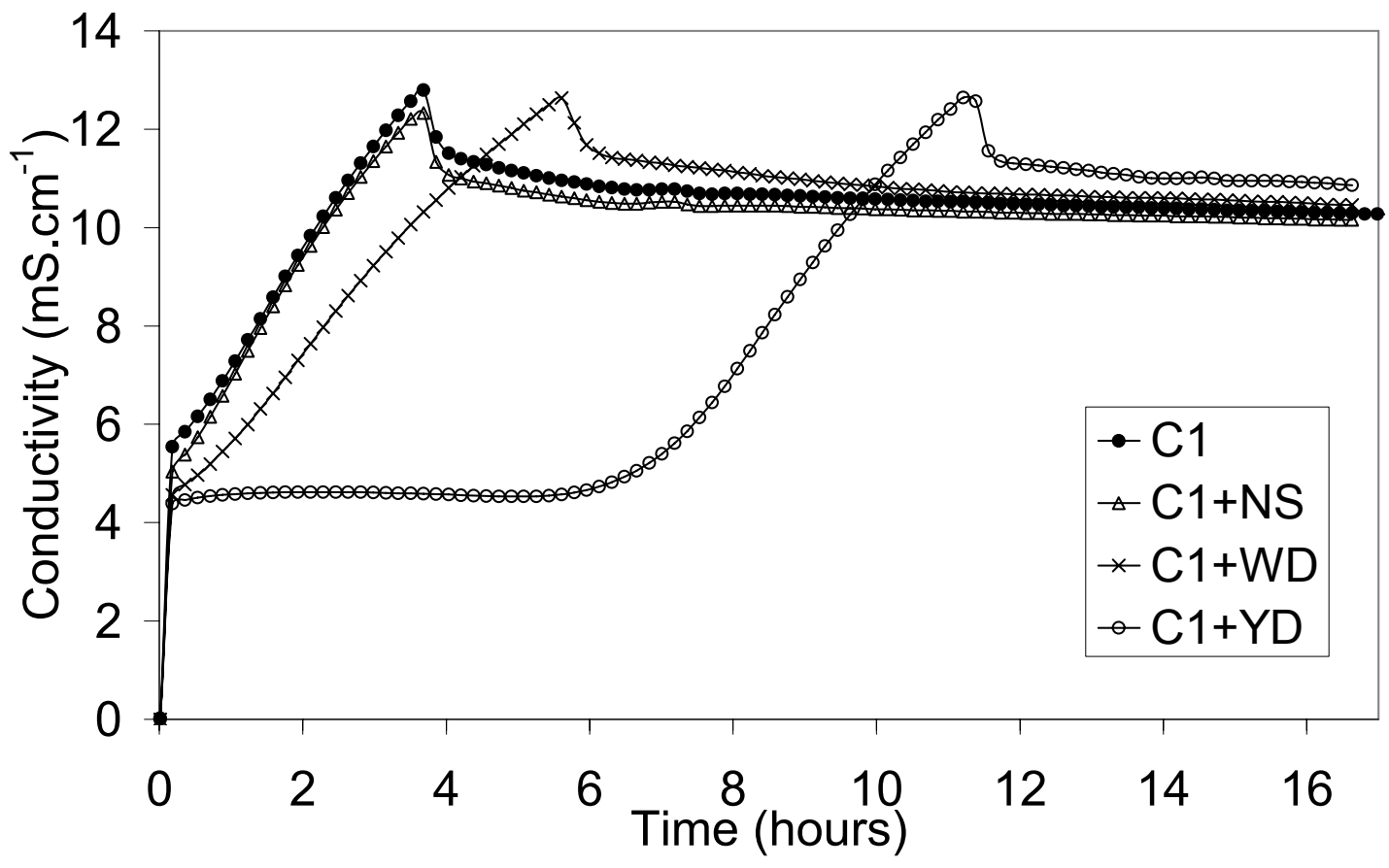


A.Peschard ${ }^{1}$, A.Govin* ${ }^{1}$, J.Pourchez ${ }^{1}$, E.Fredon ${ }^{2}$, L.Bertrand $^{3}$, S.Maximilien ${ }^{3}$, B.Guilhot ${ }^{1}$ 
Fig. 6. Effect of YD addition on cement dissolution

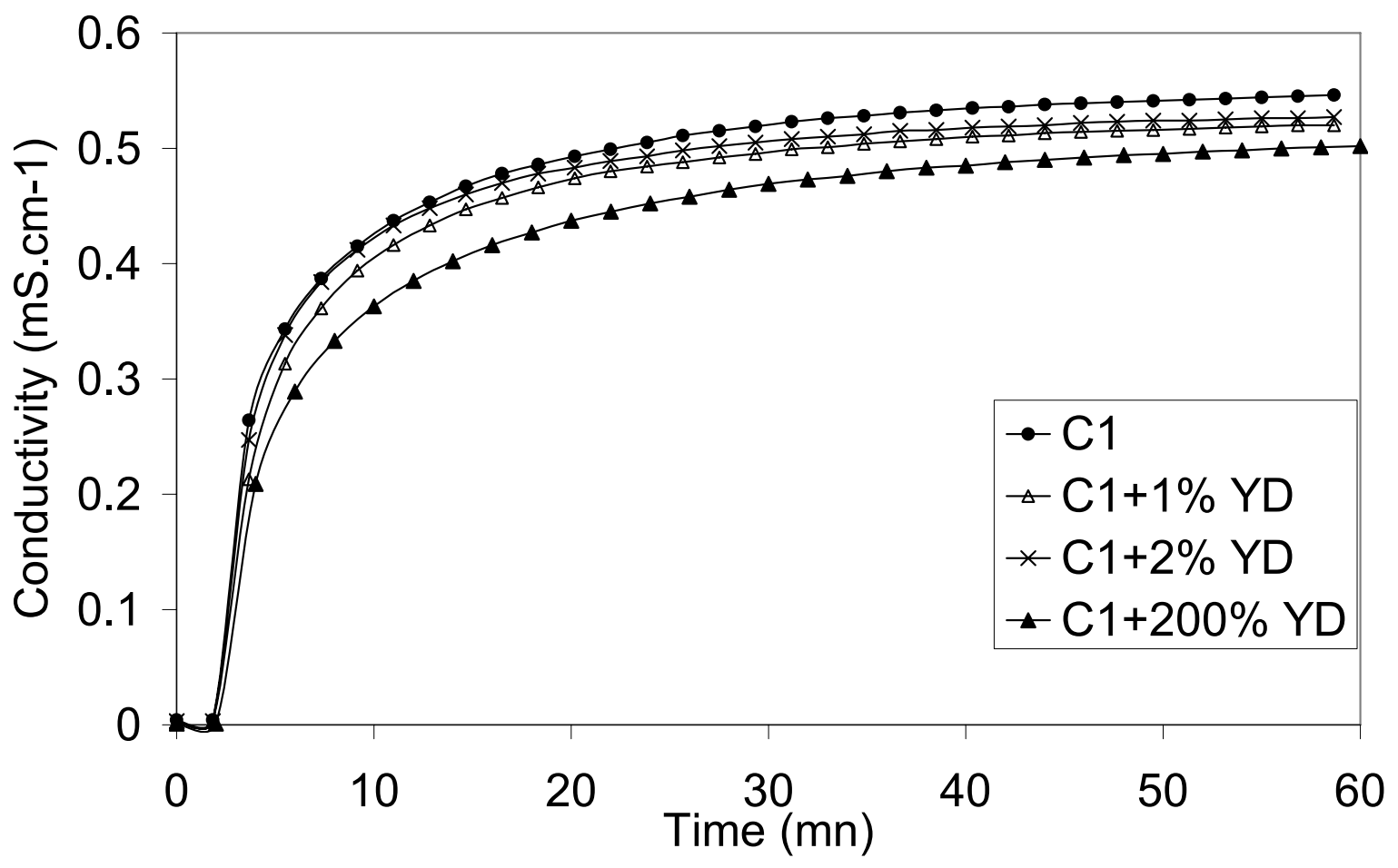


A.Peschard ${ }^{1}$, A.Govin* ${ }^{1}$, J.Pourchez ${ }^{1}$, E.Fredon ${ }^{2}$, L.Bertrand $^{3}$, S.Maximilien ${ }^{3}$, B.Guilhot ${ }^{1}$ 
Fig. 7. Evolution of Calcium concentration in admixed suspensions

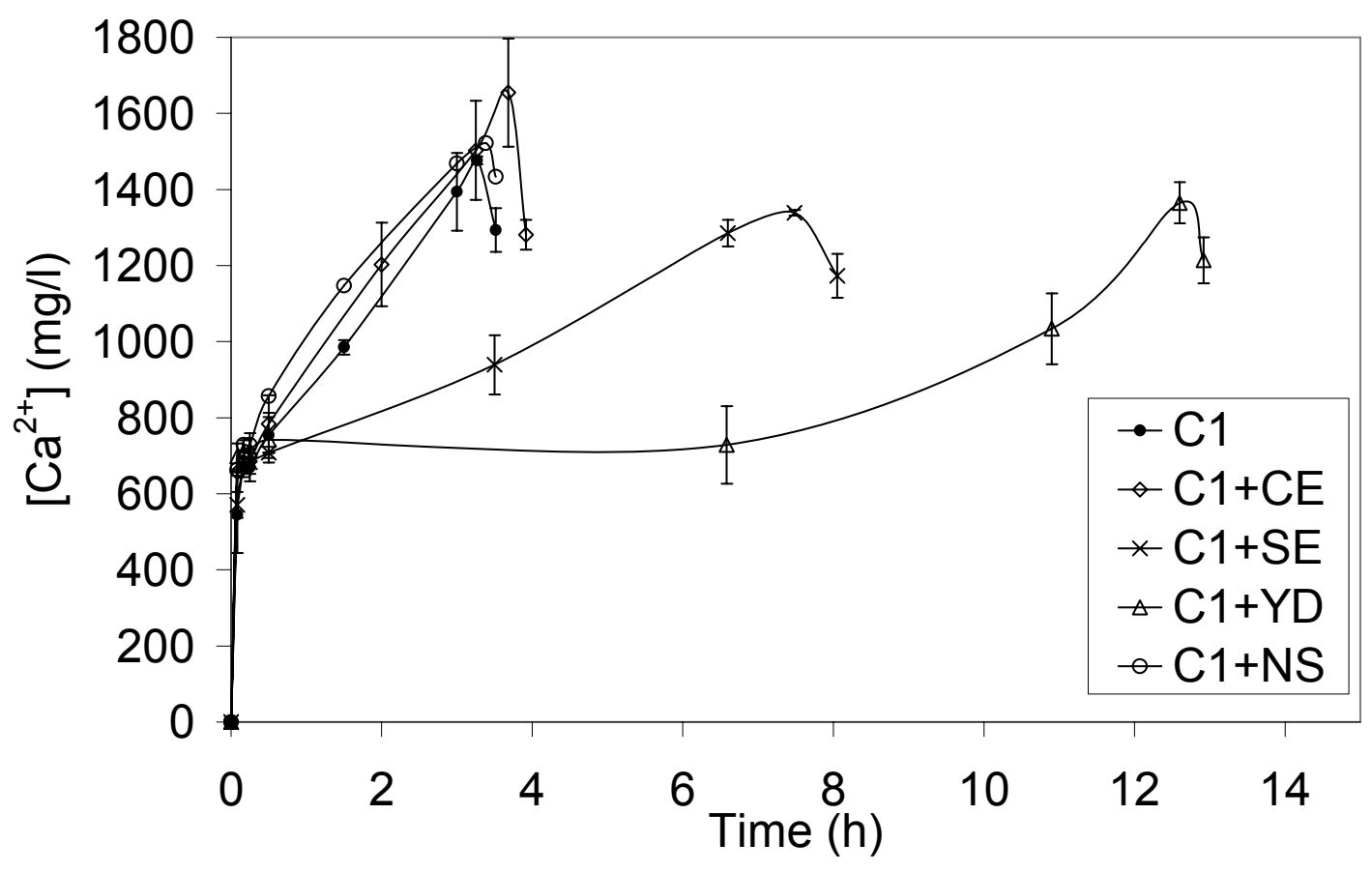


A.Peschard ${ }^{1}$, A.Govin* ${ }^{1}$, J.Pourchez ${ }^{1}$, E.Fredon ${ }^{2}$, L.Bertrand $^{3}$, S.Maximilien ${ }^{3}$, B.Guilhot ${ }^{1}$ 
Fig. 8. Evolution of sulfate concentration of admixed cement suspensions

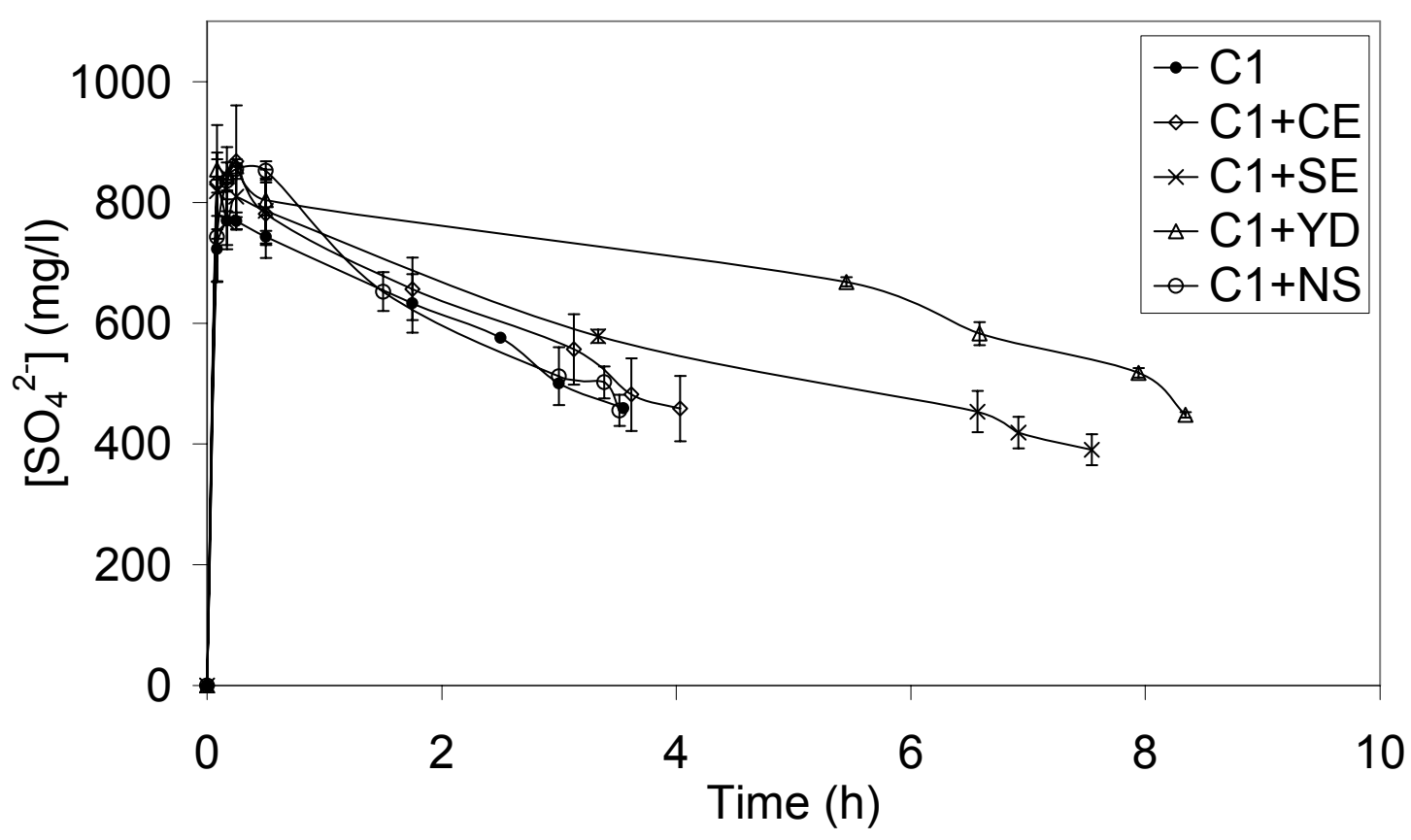


A.Peschard ${ }^{1}$, A.Govin* ${ }^{1}$, J.Pourchez ${ }^{1}$, E.Fredon ${ }^{2}$, L.Bertrand $^{3}$, S.Maximilien ${ }^{3}$, B.Guilhot ${ }^{1}$ 
Figure captions

Fig. 1. Sample preparation previous to proportioning polysaccharides in cement suspension Fig. 2. Different steps of a conductimetric curve

Fig. 3. Effect of the chemical nature of polysaccharides on cement hydration

Fig. 4. Effect of a delayed addition of $0.5 \%$ YD on cement $\mathrm{C}_{1}$ hydration

Fig. 5. Effect of dextrinization on the conductimetric curves

Fig. 6. Effect of YD addition on cement dissolution

Fig. 7. Evolution of Calcium concentration in admixed suspensions

Fig. 8. Evolution of sulfate concentration of admixed cement suspensions 
Table 1 Chemical composition and potential phases determined by Bogue approximation

\begin{tabular}{|c|c|c|}
\hline Chemical composition & $\mathrm{C}_{1}$ & $\mathrm{C}_{2}$ \\
\hline $\mathrm{SiO}_{2}$ & 22.2 & 21.9 \\
\hline $\mathrm{TiO}_{2}$ & 0.2 & 0.4 \\
\hline $\mathrm{Al}_{2} \mathrm{O}_{3}$ & 4.4 & 3.8 \\
\hline $\mathrm{Fe}_{2} \mathrm{O}_{3}$ & 0.3 & 4.3 \\
\hline $\mathrm{CaO}$ & 67.2 & 62.8 \\
\hline $\mathrm{MnO}$ & 0.01 & 0.04 \\
\hline $\mathrm{MgO}$ & 0.5 & 2.2 \\
\hline $\mathrm{Na}_{2} \mathrm{O}$ & 0.4 & 0.4 \\
\hline $\mathrm{K}_{2} \mathrm{O}$ & 0.05 & 0.39 \\
\hline $\mathrm{P}_{2} \mathrm{O}_{5}$ & 0.11 & 0.26 \\
\hline $\mathrm{SO} 3$ & 3 & 2.6 \\
\hline Bogue approximation & $\mathrm{C}_{1}$ & $\mathrm{C}_{2}$ \\
\hline $\mathrm{C}_{3} \mathrm{~S}$ & 66 & 51 \\
\hline $\mathrm{C}_{2} \mathrm{~S}$ & 14 & 24 \\
\hline $\mathrm{C}_{3} \mathrm{~A}$ & 11 & 2.6 \\
\hline $\mathrm{C}_{4} \mathrm{AF}$ & 1 & 13.2 \\
\hline
\end{tabular}


A.Peschard ${ }^{1}$, A.Govin* ${ }^{1}$, J.Pourchez ${ }^{1}$, E.Fredon ${ }^{2}$, L.Bertrand $^{3}$, S.Maximilien ${ }^{3}$, B.Guilhot ${ }^{1}$ 
Table 2 Properties of polysaccharides

\begin{tabular}{cccc}
\hline Admixture & Solubility at $25^{\circ} \mathrm{C}$ & Mw (Daltons) & Substituent \\
CE & Yes & $(11.6 \pm 0.1) 10^{6}$ & $\mathrm{CH}_{3},\left(\mathrm{CH}_{2}\right)_{2}-\mathrm{OH}$ and \\
& & $(1.48 \pm 0.05) 10^{6}$ & $\left(\mathrm{CH}_{2}\right)_{3}-\mathrm{OH}$ \\
$\mathrm{SE}$ & Yes & $(173 \pm 5) 10^{3}$ & $\left(\mathrm{CH}_{2}\right)_{3}-\mathrm{OH}$ \\
$\mathrm{NS}$ & $\mathrm{No}$ & $25,2,10^{6}$ & \\
& & $(290 \pm 6) 10^{3}$ & - \\
$\mathrm{WD}$ & $5<\mathrm{S}<35 \%$ & $(11 \pm 1) 10^{3}$ & - \\
$\mathrm{YD}$ & $\mathrm{S}>90 \%$ & $(8,5 \pm 0,5) 10^{3}$ & - \\
\hline
\end{tabular}

${ }^{a}$ determined by Gel Permeation Chromatography

b determined by Pyrolysis-Gas Chromatography-Mass Spectrometry

$\mathrm{S}$ : soluble fraction value (producers data) 


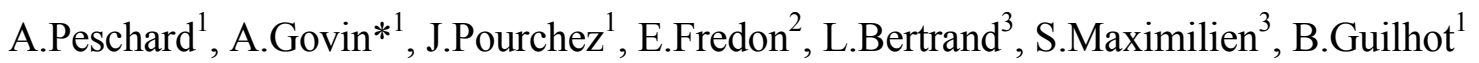


Table 3 Analysis conditions of ionic chromatography

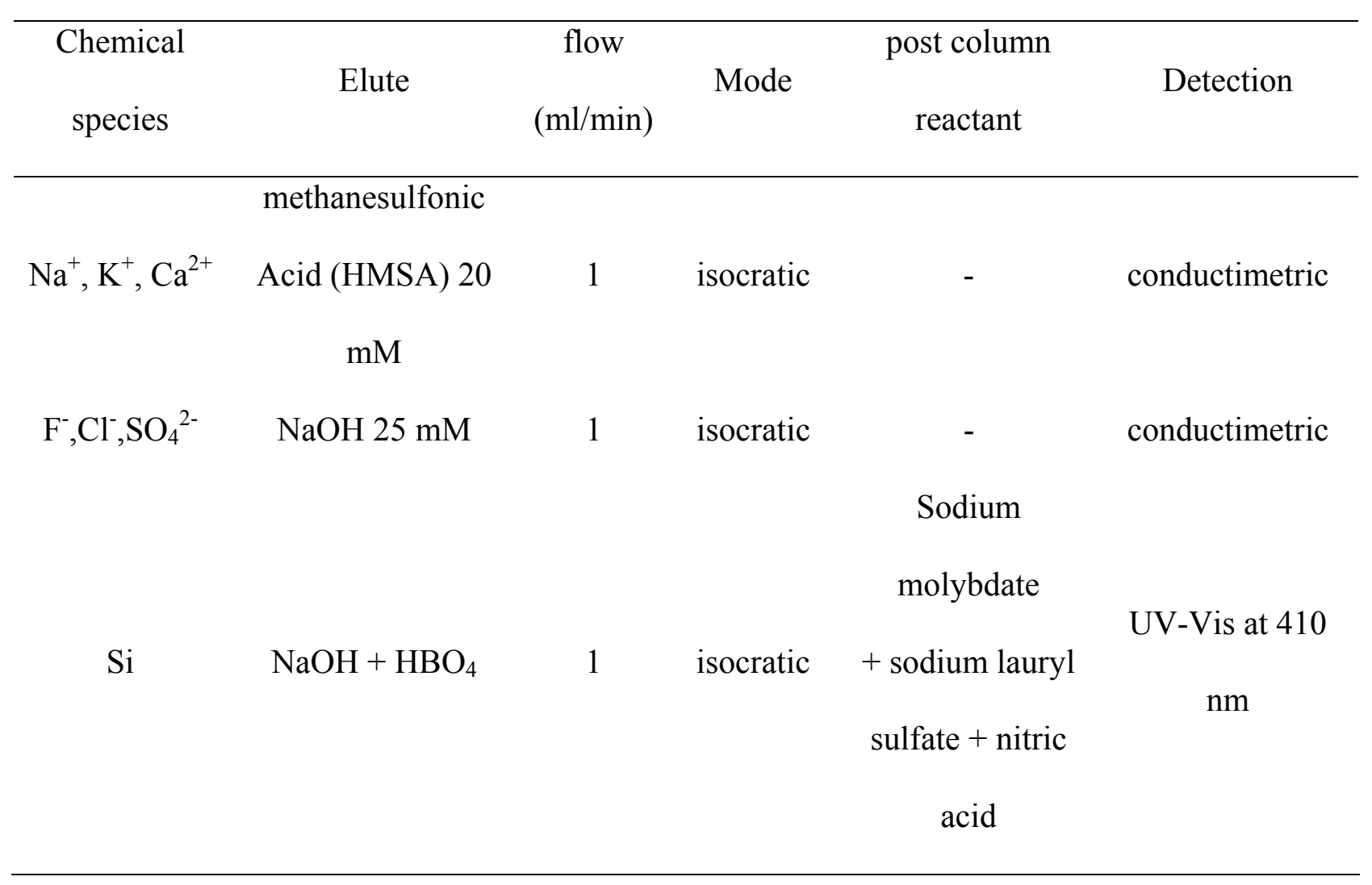




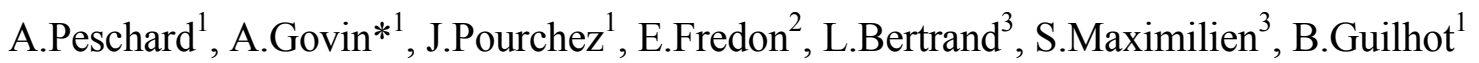


Table 4 Effect of polysaccharides and $\mathrm{P} / \mathrm{C}$ ratio on the slope, $\mathrm{t}_{\lambda \max }$ and duration of the blocking effect

\begin{tabular}{|c|c|c|c|c|}
\hline & Slope $\left(\mathrm{mS} \cdot \mathrm{cm}^{-1} \cdot \mathrm{h}^{-1}\right)$ & $t_{\lambda \max }(h)$ & $\begin{array}{l}\text { Duration of the } \\
\text { blocking effect }(\mathrm{h})\end{array}$ & $\begin{array}{c}\text { Quantity of native } \\
\text { polysaccharide in cement } \\
\text { filtrate from Eq. } 1(\%)\end{array}$ \\
\hline $\mathrm{C} 1$ & $2.6 \pm 0.2$ & $3.5 \pm 0.1$ & - & nd \\
\hline $\mathrm{C} 1+0.5 \% \mathrm{CE}$ & $2.23 \pm 0,01$ & $4.2 \pm 0.2$ & - & $80 \pm 3$ \\
\hline $\mathrm{C} 1+0.5 \% \mathrm{NS}$ & $2.3 \pm 0,1$ & $3.9 \pm 0.1$ & - & nd \\
\hline $\mathrm{C} 1+0.5 \% \mathrm{WD}$ & $1.86 \pm 0,01$ & $5.6 \pm 0.3$ & - & $90 \pm 6$ \\
\hline $\mathrm{C} 1+0.5 \% \mathrm{SE}$ & $1.1 \pm 0.1$ & $8.0 \pm 0.6$ & - & $10 \pm 3$ \\
\hline $\mathrm{C} 1+1 \% \mathrm{SE}$ & $0.8 \pm 0.1$ & $11.1 \pm 0.7$ & - & nd \\
\hline $\mathrm{C} 1+1.2 \% \mathrm{SE}$ & $0.4 \pm 0.1$ & $>17$ & - & nd \\
\hline $\mathrm{C} 1+1.5 \% \mathrm{SE}$ & $0.12 \pm 0.06$ & $>17$ & - & nd \\
\hline $\mathrm{C} 1+2 \% \mathrm{SE}$ & $0.09 \pm 0.05$ & $>17$ & - & nd \\
\hline $\mathrm{C} 1+0.1 \% \mathrm{YD}$ & $2.03 \pm 0.12$ & $4.4 \pm 0.1$ & 0 & nd \\
\hline $\mathrm{C} 1+0.3 \% \mathrm{YD}$ & $1.79 \pm 0.08$ & $6.1 \pm 0.2$ & 0 & nd \\
\hline $\mathrm{C} 1+0.4 \% \mathrm{YD}$ & $1.76 \pm 0.09$ & $7.2 \pm 0.3$ & $1.7 \pm 0.2$ & nd \\
\hline $\mathrm{C} 1+0.5 \% \mathrm{YD}$ & $2.07 \pm 0.13$ & $14 \pm 1$ & $10 \pm 1$ & $3 \pm 1$ \\
\hline $\mathrm{C} 1+1 \% \mathrm{YD}$ & nd & nd & $46 \pm 4$ & nd \\
\hline
\end{tabular}




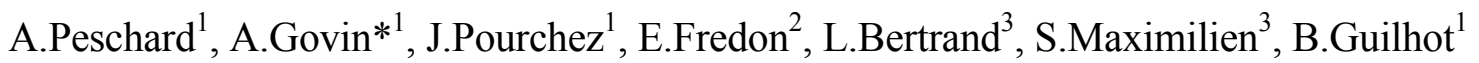




\section{Table captions}

Table 1 Chemical composition and potential phases determined by Bogue approximation Table 2 Properties of polysaccharides

Table 3 Analysis conditions of ionic chromatography

Table 4 Effect of polysaccharides and $\mathrm{P} / \mathrm{C}$ ratio on the slope, $\mathrm{t}_{\lambda \max }$ and duration of the blocking effect 